\section{Reactions of Organic Halides in Solution}

WE are sorry to have again to contradict Dr. Evans, but he continues to misrepresent us ${ }^{1}$. He does so now by quoting a limited passage from a paper by one of $\mathrm{us}^{2}$, and then adding, as though it were a paraphrase, a statement of his own that does not, in fact, reproduce the meaning. The passage is dealing with the relative rates of nucleophilic halogensubstitution in $R$-Hal, where $R=\mathrm{Me}$, Et, $n-\mathrm{Pr}, i$ - Bu, neoPentyl, and, as quoted, reads : "The rate relationships for the first four members are fairly normal for the bimolecular mechanism, the rate of which is decreased by electron-accession to the reaction centre, but the introduction of the last $\beta$-methyl substituent has obviously introduced an effect which is far larger than that to be expected on the basis of its capacity for the release of electrons. . . This effect is believed to be' of steric origin." Dr. Evans continues : "This indicates that steric hindrance was considered to be unimportant in the bimolecular $S_{N} 2$ reactions of $R X$ when $R$ is methyl or ethyl". On the contrary, it "indicates" what it states, namely, that the total structural effect on rate when $R=$ neopentyl is in fact far greater than in the other cases, that Hughes could not see why the polar effect of methyl should take such a sudden jump as the last methyl is introduced, and that he could see a reason why its steric effect might do so.

Concerning Dr. Evans's historical comment that, although Hughes first estimated ${ }^{2}$ the steric compressions involved in $S_{N} 2$ reactions of $R X$ for $R=$ $\mathrm{Me}$, Et, he did not then (1941) "specifically" consider $i$-Pr and $t$-Bu, it may be remarked that, in the approximation to which we have hitherto worked, the specific consideration which was then lacking consisted only of multiplying by 2 and 3 in the respective cases, that is, duplicating and triplicating the ethyl compressions.

We thought we had previously made it clear that we were aware of the steric effect of the $\alpha$-methyl group in the bimolecular reactions of $\alpha$-methylallyl chloride, but regarded Dr. Evans's method of analysis as unsound ${ }^{3}$.

As to unimolecular reactions, Dr. Evans's method of treatment appears to be similar to that which led Baughan, Evans and Polanyi ${ }^{4}$ to the conclusion, which we believe to be incorrect, that the known inactivity of neopentyl halides in certain substitutions is a property of the ionization mechanism. Hughes established a contrary conclusion ${ }^{5}$ in 1941.

Note added in proof. The Editors of Nature have allowed us to see Dr. Evans's comment. His new quotation, like the previous one, is divorced from its context: in both, the standard of comparison was the very special group, neopentyl. It should be impossible to construe such comparisons between groups as comparisons of polar and steric effects in the same (ordinary) group, since, in the paragraph now partly quoted, calculations are reported which show appreciable steric compressions in ordinary groups.

University College of North Wales,

$$
\text { E. D. HugheS }
$$
Bangor.

\section{K. IngoLd}

University College, London.

'Evans, A. G., Nature, 158, 586 (1946); cf. ibid., 157, 438 (1946) ; cf. also Hughes and Ingold, ibid., 158, 94 (1946).

2 Hughes, Trans. Farad. Soc., 37, 621 (1941).

Hughes and Ingold, ref. 1

- Trans. Farad. Soc., 37, 377 (1941).

${ }^{6}$ Ref. 2. Cf. Dostrovsky, Hughes and Ingold, J. Chem. Soc., 17? 1946).
I sUBMIT that the interpretation given above by Profs. Ingold and Hughes for the passage which I quoted $^{1}$ is not made clear in the original text ${ }^{2}$. What I see expressed in the paper regarding the bimolecular reactions of $R$-Hal for the Me, Et, $n$-Pr, $i$ $\mathrm{Bu}$, neopentyl series can be illustrated once more by Prof. Hughes's statement that "It is therefore concluded that in addition to the retarding influence of methyl substitution, which operates throughout the series, and may be attributed essentially to the inductive effect, there is a superposed effect, which may in principle enter in all stages of $\beta$-substitution, but which assumes real importance only in the case of the neopentyl halide. This effect is believed to be of steric origin ${ }^{2} . "$

Apart from this historical question, I wish to emphasize again that, in my view, the decrease in bimolecular reaction-rate along the $\mathrm{Me}$ to $t$-Bu series is due solely to the increase in steric hindrance along this series. This point of view is developed in detail in my forthcoming papers on the subject ${ }^{3}$.

Chemistry Department, Alwyn G. Evans

University, Manchester.

1 Evans, A. G., Nature, 158, 586 (1946). Cf. Evans, A. G., ibid., 157, 438 (1946). Hughes and Ingold, ibid., 158, 94 (1946).

${ }^{2}$ Hughes, Trans. Farad. Soc., 37, 623 (1941).

${ }^{8}$ Evans, A. G., Trans. Farad. Soc., in the press. "The Reactions of Organic Halides in Solution" (Manchester University Press, 1946).

\section{A Method of Using Marked Phase Boundaries}

When iron is oxidized in air, foreign particles on the original surface of the metal will later be found imbedded in the oxide layer. From this observation Fisch beck ${ }^{1}$ concluded that iron, not oxygen, migrates through the reaction product. Starting from this fact, we have worked out the following simple method for ascertaining the direction of migration in reactions between solid substances.

On the original phase boundary a mark is made, using a substance which can be seen (at least with a microscope), does neither lessen the contact between the reaction partners nor react with them, does not act on the reaction product and does not change in any way, physically or chemically, during the process. It should, therefore, be observable after the reaction. The migration of matter is then recorded directly from the position of the mark in relation to the starting materials and the reaction product.

The method has been found suitable when studying the systems magnesium oxide/magnesium pyrophosphate ${ }^{2}$, lead oxide/lead silicate ${ }^{3}$, lead oxide/lead sulphat $\theta^{4}$ and zinc oxide/aluminium oxides, using platinum for marking ; and the system silver/sulphur ${ }^{5}$, using gold.

\section{ROBERT JAGITSCH}

Department of Chemical Technology,

Chalmers Institute of Technology, Gothenburg.

Dec. 4.

${ }^{1}$ Fischbeck, K., Metallwirtsch., 14, 733 (1935).

'Jagitsch, R., and Perlström, G., Arkiv Kemi, Min., Geol., 22A, No. 5 (1946).

sagitsch, R., and Bengtson, B., Arkiv. Kemi, Min., Geol., 22A, No. 6 (1946).

- Jagitsch, R., and Mattsson, B., unpublished results.

sengtson, B., and Jagitsch, R., Arkiv Kemi, Min., Geol., in the press. 